\title{
MEMÓRIA E IDENTIDADE DO POVO NO ROMANCE SOCIO-HISTÓRICO LES MISÉRABLES: A PERSONAGEM ENJOLRAS ${ }^{1}$
}

Maria Júlia Pereira Mestranda em Estudos Literários pela UNESP majuper@gmail.com

${ }^{1} \mathrm{O}$ presente trabalho foi realizado com apoio do CNPq. 
RESUMO

Les Misérables (1862), de Victor Hugo, é um romance socio-histórico que versa sobre uma série de questões políticas e sociais da França do século XIX. O conceito de "povo" (DALLARI, 2011), bem como a construção de sua memória e identidade (POLLAK, 1992) estão, pois, no romance, integrados à insurreição republicana de junho de 1832. Neste artigo, pretende-se demonstrar como a personagem Enjolras, por meio de sua constituição, ação e transformação, ao evocar a memória e contribuir para a consolidação da identidade do povo, encarna-o e o representa.

Palavras-chave: memória e identidade, povo, Les Misérables, personagem Enjolras.

\section{RÉSUMÉ}

Les Misérables (1862), de Victor Hugo, est um roman socio-historique traitant de nombreuses questions politiques et socioéconomiques dans la France du XIXe siècle. Le concept de "peuple» (DALLARI, 2011), ainsi que la construction de as mémoire et de son identité (POLLAK, 1992), sont, ainsi, dans le roman, intégrés à l'insurrection républicaine du 5 juin 1832. Dans cet article, on souhaite exposer comment le personnage Enjolras, à travers sa constitution, son action et sa transformation, incarne et represente le peuple em évoquant as mémoire et em contribuant à la consolidation de son identité.

Mots-clés: mémoire et identité, peuple, LesMisérables, personage Enjolras.

\section{INTRODUÇÃO}

Les Misérables (1862), corpus deste trabalho, é um romance histórico (LUKÁCS, 2011) com temática de cunho social (CARPEAUX, 1978), composto por cinco tomos, que apresentam diversos livros, os quais, por sua vez, são subdivididos em vários capítulos. Considerando toda essa extensão e os limites impostos a este trabalho, foram eleitas as cenas do romance relativas à apresentação do grupo "Os amigos do $A B C$ ", o aparecimento da personagem Enjolras e os momentos em que ela age e discursa em meio à luta pela insurreição republicana, representando e evocando a memória no processo de consolidação da identidade do povo.

Diante disso, foram selecionados, principalmente: o Livro Quarto "Os amigos do ABC", do Tomo III (Marius) e os Livros Primeiro "Algumas páginas de história", Décimo "5 de junho 
de 1832", Décimo Primeiro "O átomo fraterniza com a tempestade", Décimo Segundo "Corinthe" e Décimo Quarto "As grandezas do desespero", todos do Tomo IV (O Idílio da Rua Saint-Plumet e a Epopeia da Rua Saint-Denis), além do Livro Primeiro "A guerra entre quatro paredes", do Tomo V (Jean Valjean).

É importante frisar que, neste texto, não se pretende desenvolver detalhada e aprofundadamente a trajetória da personagem Enjolras, mas apenas versar sobre sua constituição, ação e transformação - enquanto líder e representante dos insurgentes - no que diz respeito à memória e à identidade do povo no romance.

Para a abordagem pretendida neste artigo, é fundamental tratar, ainda que brevemente, do conceito de povo e da relação entre memória e identidade. Para isso, serão expostas aqui as definições da palavra "povo" encontradas no Dicionário Houaiss da Língua Portuguesa (2009) e as considerações de Dalmo de Abreu Dallari (2011) sobre o desenvolvimento histórico desse conceito, a noção jurídica que o circunda, e, ainda, como a cidadania a ele se articula. A relação entre memória e identidade, por sua vez, será discorrida sob a luz de Memória e identidade social (1992), de Michael Pollak.

Para discutir a personagem Enjolras, abordar-se-á sua constituição, ação e transformação. Fundamentais à narrativa, as personagens romanescas assumem importante papel na disposição das histórias, pois não apenas determinam as ações, mas também as vivenciam e as conectam, conferindo-Ihes sentido. Conforme Reuter (1996), de certo modo, é possível afirmar que toda história é a história das personagens, sendo sua análise fundamental para a compreensão dos processos narrativos.

\section{O CONCEITO DE POVO E A RELAÇÃO ENTRE MEMÓRIA E IDENTIDADE}


O Dicionário Houaiss da Língua Portuguesa (2009, p. 1534) apresenta dez definições para a palavra "povo". Para os fins deste trabalho, seguem as duas primeiras, e, portanto, as mais recorrentes, e também a quinta e a sexta:

1 conjunto de pessoas que falam a mesma língua, têm costumes e interesses semelhantes, história e tradição comuns $<0$. brasileiro $><0$. russo $>\mathbf{2}$ conjunto de pessoas que vivem em comunidade num determinado território; nação; sociedade [...] 5 conjunto de cidadãos de um país em relação aos governantes 6 conjunto de pessoas que pertencem à classe mais pobre; plebe $[\ldots]$

As definições iniciais distanciam-se da noção jurídica desse conceito, surgida com o Estado moderno e consolidada com o lluminismo. Assim, aproximam-se do que Dallari (2011, p. 100-101) denomina população: trata-se do elemento pessoal numérico e demográfico que constitui o Estado, não devendo ser entendido como sinônimo de povo, justamente por não expressar o "vínculo jurídico entre a pessoa e o Estado". Dessa forma, dizem mais respeito ao conceito de "nação" - "pertinência a uma comunidade históricocultural" - que ganhou força após a Revolução Francesa, sobretudo com o Romantismo, e que, apesar de ter sido fundamental para o surgimento do termo jurídico "nacionalidade", é impróprio enquanto sinônimo de povo.

De fato, somente a partir do Estado moderno - monárquico e absoluto - generalizouse, especialmente na França, a noção de cidadão, a qual influiu na ampliação do conceito de povo. Após as revoluções do século XVIII, que marcaram a ascensão política da burguesia, a palavra "povo" surge nos textos constitucionais desvinculada da ideia aristocrática de casta, buscando-se, dessa forma, evitar, ainda que apenas no plano formal, a exclusão de certos 
componentes do Estado. Ou seja, afirmou-se "em termos jurídicos a extensão da plena cidadania" (DALLARI, 2011, p. 103).

Seguindo os princípios estabelecidos pelo jurista alemão Georg Jellinek, Dallari (2011, p. 104) afirma que, juridicamente, “o povo é o elemento que dá condições ao Estado para formar e externar uma vontade". Tal conceito se refere ao conjunto de indivíduos que constituem o Estado e estabelecem com ele um "vínculo jurídico de caráter permanente" por meio da formação de sua vontade e do exercício do poder soberano. Nesse sentido, aqueles que são parte desse Estado, em decorrência de tal vínculo, adquirem a condição de cidadãos, sendo possível, portanto, conceituar "povo como o conjunto de cidadãos do Estado".

Em Les Misérables, ao apresentar o grupo de amigos denominado Les Amis de l'ABC (os amigos do ABC), Victor Hugo (2013, p. 732) expressa: “L'Abaissé, c'était le peuple" (O diminuído era o povo). "Abaissé" pode ser entendido como rebaixado, diminuído, e, em sentido antigo, como o estado de quem perdeu a dignidade (TROUILLEZ, 2013, p. 1). Nessa acepção, o conceito de povo apresentado por Hugo coincide com a sexta definição - acima mencionada - do Dicionário Houaiss; isto é, trata-se das pessoas que pertencem à classe mais pobre, rompendo com o conceito aristocrático de povo ligado à casta.

No entanto, a definição de povo enquanto cidadãos de um Estado coexiste, em Les Misérables (HUGO, 2013, p. 729-743), com a de povo como as camadas mais desfavorecidas da população. Isso fica claro quando os amigos do $A B C$, autodenominados por meio desse jogo de palavras, intitulam-se como "os amigos do povo", seus representantes e defensores,

\footnotetext{
${ }^{2}$ As letras ABC pronunciadas seguidamente soam, em francês, exatamente como a palavra abaissé.
} 
havendo entre eles não apenas os estudantes de origem burguesa, partidários dessa causa, mas também os operários que sofriam para ganhar três soldos por dia de trabalho.

Diante disso, a personagem Enjolras, jovem que, apesar de "filho único e rico", é o "soldado da democracia" e lidera esse grupo de insurgentes - "os amigos do ABC" - nas barricadas (HUGO, 2013, p. 733). Trata-se de uma personagem que defende a insurreição republicana como meio legítimo de pôr abaixo uma ordem que não representa o povo. Ou seja, Enjolras se reconhece nos cidadãos da pátria, que se encontram diminuídos em sua dignidade, marginalizados e excluídos de um governo monárquico incapaz de representá-los e, portanto, de atender a seus anseios.

A memória, por sua vez, remete a um "fenômeno individual". Todavia, também pode ser compreendida como um "fenômeno coletivo e social", "construído coletivamente", sendo constituído por acontecimentos, pessoas e até mesmo personagens. O processo de construção da memória demonstra uma relação fenomenológica estreita entre esta e a identidade: é possível dizer que "a memória é um elemento constituinte do sentimento de identidade, tanto individual como coletiva, na medida em que ela é também um fator extremamente importante do sentimento de continuidade e de coerência de uma pessoa ou de um grupo em sua reconstrução de si" (POLLAK, 1992, p. 203-204).

No romance histórico LesMisérables, o conceito de povo é apresentado a partir das duas últimas acepções mencionadas - cidadão e plebe - e sua memória e identidade são evocadas quando a personagem Enjolras, liderando o grupo os amigos do $A B C$, encarna esse conceito ao representar sua causa, optando por um trágico fim - sua morte - na luta pela insurreição republicana. Assim, a partir de uma abordagem historiográfica do cenário 
político francês entre 1815 - após a queda do império napoleônico - e 1832 - ano da insurreição republicana de 5 de junho - o romance trata de acontecimentos que têm o povo como centro e que compõem sua memória, além de contemplar sua identidade na condição de cidadãos e miseráveis.

\section{APONTAMENTOS SOBRE A PERSONAGEM E O ROMANCE SOCIO-HISTÓRICO LES MISÉRABLES, DE VICTOR HUGO}

Segundo Antonio Candido (2002, p. 51-52), a leitura de um romance leva seus leitores, inevitavelmente, a associar a série de fatos que compõe a história às personagens, já que são elas que vivem esses fatos. Assim, a história existe por meio das personagens, que nela estão vivas. Juntas, exprimem "a visão da vida" que decorre do romance, "os significados e valores que o animam". Além do mais, "a personagem é um ser fictício", paradoxo sob o qual acontece a criação literária. A verossimilhança no romance depende da possibilidade de tal ser, criação imaginária, transmitir uma impressão genuína da "verdade existencial”. Dessa maneira, é possível inferir que a personagem é a concretização do próprio romance, pois manifesta a "relação entre o ser vivo e o ser fictício".

A partir das personagens a ficção se torna inegável; isto é, elas conferem certa concretude à camada imaginária, tornando evidente a construção ficcional. Na narrativa, o narrador aparenta se diferenciar da personagem, podendo, assim, surgir "formas de discurso ambíguas", pensadas simultaneamente a partir da perspectiva da personagem e do narrador fictício. Por isso, há no texto ficcional sinais linguísticos que revelam, por meio da personagem, como "o narrar épico é estruturalmente de outra ordem que o enunciar do historiador, do correspondente de um jornal ou de outros autores de enunciados reais". 
Dentre esses sintomas estão os usos de advérbios de tempo, verbos caracterizadores de processos psíquicos, discurso indireto livre e a manutenção da terceira pessoa. Ao serem organizados conjuntamente, esses indícios linguísticos atuam de modo a possibilitar a coexistência da perspectiva das personagens - produtora de seus pensamentos - e do relato impessoal do narrador (ROSENFELD, 2002, p. 21-25).

As pessoas reais são determinadas, ou seja, a cognição em relação à pessoa real é limitada no sentido da impossibilidade de se exaurir toda a complexidade que a constitui. A personagem do romance, por sua vez, é psíquica e fisicamente uma conformação esboçada, delineada como um indivíduo absolutamente delimitado. É justamente graças a tal conformação que as personagens alcançam a universalidade sem diminuir sua singularidade, sua individualidade sensível, possibilitando, na fruição estética, a apreciação e o compartilhamento emocional, visto que o leitor experimenta humanamente possibilidades que a vida pessoal dificilmente lhe permitiria experimentar (cf. ROSENFELD, 2002, p. 32-46).

Nessa mesma perspectiva, Antonio Candido (2002, p. 58-65) expõe que só é possível ter uma visão parcial em relação às pessoas reais, pois a vida impõe a todos a impossibilidade de apreender tudo o que constitui "o modo de ser de uma pessoa". Porém, no romance, essa visão parcial é criada pelo autor que esboça a personagem numa estrutura determinada e elaborada, limitando o conhecimento possível em relação a ela. Para isso, o escritor seleciona falas, "gestos", "objetos significativos", dentre outras marcas que permitem ao leitor identificar a personagem, sem prejuízo de "complexidade e riqueza" na narrativa. 
Quanto à mencionada identificação da personagem pelo leitor, é interessante assinalar o entendimento de Walter Benjamim (1985, p. 213-214) de que a essência das personagens do romance reside em sua própria morte, em seu próprio fim, ou seja: limitada em sua finitude, a personagem é portadora de um "sentido da vida". O leitor do romance busca justamente pessoas nas quais possa ler tal sentido. Isso significa que ele necessita assegurar sua participação na "morte" da personagem, seja figurativamente - o fim do romance - ou literalmente - "a morte verdadeira".

Muito possivelmente, a busca do leitor pelo sentido que a personagem expressa no romance, seja por meio de sua constituição ou de suas ações e transformações, é o que possibilita, na fruição estética, a "empatia simpática com a vida da personagem" mencionada por Bakhtin (2003, p. 75). Essa experiência se manifesta na medida em que o leitor vivencia externamente "tanto a vida exterior quanto a interior" do "outro", combinando-as em um plano único.

As personagens no romance histórico constituem parte de sua própria caracterização como histórico. Isso se dá devido à exigência de que o curso das personagens principais esteja irrecorrivelmente vinculado "ao destino da comunidade histórica de que fazem parte". Dessa maneira, nesse tipo de romance a personagem representa o componente mais relevante e os acontecimentos históricos estão intimamente ligados ao destino dos protagonistas (BASTOS, 2007, p. 13-86). Assim, em Les Misérables, a sorte da personagem Enjolras e dos demais insurgentes por ele liderados é a mesma dos revolucionários de junho de 1832 massacrados pelo regime monárquico - a comunidade histórica da qual fazem parte. 
Quanto ao romance histórico - assim conhecido por ser dotado de uma abordagem historiográfica - é importante assinalar que sua expressão mais bem delineada se deu por volta de 1814 - quando do fim das guerras napoleônicas - com Walter Scott. Pois é a partir da obra de Scott que aparece o "elemento especificamente histórico" fundamental: "a particularidade dos homens ativos" oriunda da singularidade histórica de seu tempo. Todo esse movimento deriva de uma mudança, surgida a partir do lluminismo, da própria concepção de História (LUKÁCS, 2011, p. 33).

Os cenários político, ideológico e socioeconômico, além da consumação das revoluções burguesas, engendraram, na França, a consolidação de fato de um Estado nacional, e, consequentemente, de um sentimento de "patriotismo revolucionário" que implicou a produção de uma série de obras importantes. Nesse sentido, é a partir da Revolução Francesa e de seus desdobramentos - as guerras revolucionárias, a ascensão e a queda de Bonaparte - que a História passa a ser entendida como experiência das massas em escala européia (LUKÁCS, 2011, p. 37-38) e até mesmo universal.

Dessa forma, a própria existência humana passa a ser apreendida "como algo historicamente condicionado" e a História deixa de ser algo meramente pertencente a indivíduos isolados para se tornar fator determinante da vida cotidiana coletiva (LUKÁCS, 2011, p. 40). As diversas convulsões sociais na França, inclusive a insurreição de caráter republicano retratada em Les Misérables, impactam diretamente na vida do povo, o qual passa a perceber a relação de tais convulsões com a queda do Antigo Regime engendrada pela Revolução Francesa. 
Victor Hugo é criticado devido ao distanciamento de sua prosa, no romance histórico, em relação a Walter Scott. No entanto, apesar de prevalecer nos romances históricos de Hugo uma espécie de "subjetivismo moralizador" típico do Romantismo, o autor vai além, "política e socialmente, das finalidades reacionárias de seus contemporâneos românticos" (LUCÁKS, 2011, p.101). E produziu, em sua maturidade, dois grandes romances históricos tardios na vertente da literatura humanista de protesto: Les Misérables e Quatrevingt-treize (1793), nos quais a História é abordada pela perspectiva do "espírito humanista contestador". Em Les Misérables o povo é autenticamente retratado, e, apesar da abordagem "estilizada e romântica", ganha sentido diferente do fornecido "por qualquer outra obra de autor romântico (inclusive do jovem Hugo)" (LUCÁKS, 2011, p. 313).

No que diz respeito à literatura humanista, é importante notar que, após 1830, surgiu, na França, um Romantismo socialmente engajado por meio da denúncia da questão social, contrário aos poderes estabelecidos e defensor dos marginalizados. Essa oposição teve duas descobertas importantes: o feminismo, ainda que em defesa do direito de mulheres de uma única classe; e o proletariado, que não teve seus direitos defendidos, mas apenas a exposição de sua miséria. Les Misérables, de 1862, foi o último romance desse tipo (cf. CARPEAUX, 1978, p. 164), o que o torna efetivamente socio-histórico. Tal obra se caracteriza como um romance-epopeia carregado de certo "radicalismo populista" que teve forte ressonância entre os franceses, enquanto seu autor é o "poeta da democracia republicana" (CARPEAUX, 2008, 1621-1622), a qual teve, na França, expressão política de fato e de direito após a queda de Napoleão III - a partir da denominada Terceira República. 
Portanto, conforme será abordado no próximo tópico, em LesMisérables,aparece claramente o apelo popular pela democracia republicana: o retrato do povo construído ao longo da narrativa traz acepção singular - o povo francês, composto de seus cidadãos - e universal - os povos que são cidadãos do mundo. Além disso, a presença de heróis dignos de representá-los no combate republicano evidencia exatamente o caráter democrático dessa luta utópica e humanista, fundamentada na busca de uma sociedade fraterna, justa e capaz de promover a equidade.

\section{ANÁLISE DO CORPUS}

É importante assinalar que, em Les Misérables, a palavra insurreição aparece sessenta e seis vezes no singular e quatro vezes no plural. Em dois terços das vezes, a palavra é empregada no sentido da ação; e em um terço aparece como referência aos movimentos de insurreição (PARENT, 2013, p. 131). Na obra, Hugo (2013, p. 1194-1199) define o movimento de junho de 1832 como uma insurreição, distinguindo-a do motim, o qual considera um equívoco. Para o autor, somente a insurreição é legítima, pois, "nos Estados democráticos, os únicos fundados na justiça", pode acontecer que uma fração usurpe o poder. Diante disso, a reivindicação do que é de direito pode levar à tomada de armas: a insurreição deve se fazer presente quando a soberania coletiva estiver ameaçada - "às vezes, insurreição é ressurreição".

As sociedades secretas como os amigos do $A B C$ reuniam-se para discutir as questões políticas e socioeconômicas que afligiam a coletividade (HUGO, 2013, p. 749). Todo o processo de formação e organização da insurreição é construído pelo povo, que se organizava fabricando munições e planejando ataques (HUGO, 2013, p. 955). 
Posteriormente, as reuniões tinham como fim a decisão das estratégias de luta. Todas as questões desencadeadoras da revolução eram tidas como legítimas por Enjolras, pois eram o que permitiria ao povo retomar seu direito político em meio ao clamor revolucionário (HUGO, 2013, 961-965).

A personagem Enjolras é apresentada como o líder revolucionário que se preocupa com as injustiças que recaem sobre os cidadãos, que luta pela pátria, pela república e pela liberdade. Trata-se de um jovem sério, virtuoso e verdadeiramente comprometido com a causa política de sua pátria: a democracia e a república. Assim, essa personagem é constituída a partir daquilo que Candido (2002, p. 70-71) denomina "transposição de um modelo que o escritor reconstitui indiretamente" por meio de documentos ou testemunhos - algo muito típico dos romances históricos. Tal personagem é inspirada no modelo do jovem estudante universitário parisiense, que, envolvido com os grupos de oposição ao governo monárquico, organizava, junto aos operários e outros opositores populares, movimentos de insurreição, recorrentes na França entre 1830 e 1848 (HUGO, 2013).

Ao liderar, nas barricadas da insurreição de junho de 1832, os amigos do $A B C$ sociedade que queria educar as crianças e reerguer os homens - Enjolras lidera toda a coletividade, "representa a lógica da revolução", e, assim, o próprio povo (HUGO, 2013, p. 732-734). Dessa maneira, ele encarna a virtude política apontada por Montesquieu (1995, p. 32-45) como fundamental à república democrática, capaz de contemplar aquele que a constitui - o povo. Essa é a razão pela qual luta por essa forma de governo: o único lugar em que vislumbra a possibilidade de se concretizar uma sociedade baseada na equidade, e, 
portanto, justa. Nesse sentido, quando mata um homem que descumprira as regras, ele convoca o povo - com uso do vocativo "cidadãos" - a encarar a insurreição com seriedade:

Cidadãos, diz Enjolras, o que esse homem fez é assustador e o que fiz é horrível. Ele matou, e é por isso que o matei. Eu tive que fazê-lo, pois a insurreição deve ter sua disciplina. O assassinato é ainda mais um crime aqui do que fora daqui; nós estamos sob o olhar da revolução, somos os padres da República, as hóstias do dever, e não se deve possibilitar que caluniemos nosso combate. [...]

Executando esse homem, obedeci à necessidade; mas a necessidade é um monstro do velho mundo; a necessidade se chama Fatalidade. Ora, a lei do progresso é que os monstros desapareçam diante dos anjos e que a fatalidade se desvaneça diante da fraternidade. É um mau momento para pronunciar a palavra amor. Não importa, eu a pronuncio e a glorifico. Amor, tu tens o futuro. Morte, eu me sirvo de ti, mas te odeio. Cidadãos, não haverá no futuro nem trevas, nem relâmpagos, nem ignorância feroz, nem talião sangrento. Como não haverá mais Satã, não haverá mais Miguel. No futuro ninguém matará, a terra resplandecerá, o gênero humano amará. Ele virá, cidadãos, o dia em que tudo será concórdia, harmonia, luz, alegria e vida, ele virá. E é para que ele venha que nós iremos morrer (HUGO, 2013, p. 1266-1267, tradução nossa).

Ao mencionar o futuro, Enjolras evoca o passado e o presente: a promessa de tempos melhores surge da comparação histórica em relação aos acontecimentos passados e presentes - o momento em que se encontram. A luta pela república é um fato necessário para compor a memória e, assim, a identidade do povo, pois marca uma transformação - um renascer que passa pela fatal necessidade da morte de todos aqueles que ali o representam, concretizando, assim, o mesmo destino dessas personagens e da comunidade histórica - os revolucionários massacrados pelo regime monárquico - da qual são parte.

Nesse sentido, no momento próximo da morte dos envolvidos na insurreição, quando as munições estavam prestes a acabar e a guarda real pronta para tomar a barricada, 
Enjolras, no ápice de sua melancolia, invoca mais uma vez a memória do povo nesse processo de consolidação de sua identidade:

Cidadãos, vós imaginais o futuro? As ruas das cidades inundadas de luzes, ramos verdes sobre as soleiras, as nações irmãs, os homens justos, os velhos abençoando as crianças, o passado amando o presente, os pensadores em plena liberdade, os crentes em plena igualdade, tendo o céu como religião [...] a todos o trabalho, para todos o direito, sobre todos a paz, não mais sangue derramado, não mais guerras, as mães felizes. [...] Cidadãos, para onde vamos? [...] Vamos para a união dos povos; para a unidade do homem. [...] tu, Feuilly, valente operário, homem do povo, homens do povo. Eu te venero. Sim, tu vês com clareza os tempos vindouros, sim, tu tens razão. Tu não tinhas nem pai, nem mãe, Feuilly; tu adotaste como mãe a humanidade e como pai o direito. [...] Amigos, o momento em que nos encontramos e em que vos falo é sombrio, mas essas são as aquisições terríveis do futuro. Uma revolução é um pedágio. Oh! O gênero humano será liberto, reerguido e consolado! Nós o afirmamos sobre esta barricada. De onde sairá o grito de amor, se não do alto do sacrifício? [...] (HUGO, p. 1352-1353, tradução nossa).

Importante notar que Enjolras se dirige à Feuilly - o órfão operário, o mais legítimo representante do povo, pois vive diretamente a realidade que aflige toda a massa de miseráveis que o compõe. Feuilly é também quem faz, em meio à revolução, a gravura "Vivam os povos" (Vivent les peuples) (HUGO, 2013, p. 1339), em referência universal aos cidadãos miseráveis do mundo. Nessa perspectiva, Parent (2013, p. 8-9) afirma que o povo na condição de miserável, insurgente e principal interessado nas questões políticas e sociais tratadas no romance - é o destinatário final a quem Hugo se dirige. Assim, todo o discurso de amor à república e à insurreição, além da morte dos jovens insurgentes, são uma "resposta política ao suicídio sentimental do Werther de Goethe".

No entanto, o "suicídio" desses heróis é um autossacrifício pela causa, como Enjolras evidencia em seu discurso - é um mal necessário, uma fatalidade em nome de um bem 
maior - a luta pela insurreição reverberará no futuro, possibilitando um governo justo e que contemple seus cidadãos. É por isso que ele idolatra o amor: o amor romântico é aqui voltado à república e à democracia, sendo fundamento dessa utopia - a crença de que a luta, compondo a memória do povo, consolidará sua identidade futuramente e inspirará o progresso humano.

Apesar da postura utópica, Enjolras, a partir de sua sensibilidade, apreende a realidade que o cerca e exerce seu papel nela, o que permite aproximá-lo da noção de personagem do escritor Henry James, apresentada por Zéraffa (2010, p. 61): personagem construída a partir da "consciência-registro" - refletindo em seu conjunto a realidade vista - e da "consciência reflexiva" - refletindo a si mesma não como "ser solitário", mas como ser que reconhece que o "olhar sobre si" depende daquilo que almeja e "do olhar que outras pessoas projetam sobre ela", isto é, uma consciência apreende um "espaço social" que "necessariamente a forma".

Nesse sentido, tal personagem "mediatiza o mundo" e é simultaneamente “mediatizada por outrem” (ZÉRAFFA, 2010). Enjolras almeja um governo para o povo e lidera a luta dividindo as tarefas na insurreição, profere seus discursos e se faz modelo no seio da revolução - em sua ação, desempenha a tarefa de transformar a realidade na condição de exemplo para os insurgentes que nele confiam - como lhe diz Combeferre, um dos combatentes, na barricada: "Partilharemos de sua sorte" (HUGO, 2013, p. 1266). E é assim, portanto, que os heróis, inspirados em seu líder, escolhem viver, lutar e morrer pela causa do povo na busca por uma forma de governo republicana, democrática, justa e apta a contemplar seus cidadãos. 


\section{CONSIDERAÇÕES FINAIS}

A análise proposta neste artigo pretendeu inferir como a memória e a identidade do povo - cidadãos em acepção universal (mundo) e particular (França) - são abordadas no romance Les Misérables (1862), de Victor Hugo, por meio da constituição, ação e transformação da personagem Enjolras na luta pela insurreição republicana tratada na obra.

Considerando a estreita relação entre memória e identidade, na medida em que a memória compõe a identidade também em nível coletivo, buscou-se evidenciar que a personagem Enjolras, ao escolher, junto ao grupo que lidera - os amigos do $A B C$ (povo) - ser um representante da coletividade, torna-se agente transformador da realidade política que o circunda, evocando a memória do povo e contribuindo para a consolidação de sua identidade na busca pela república democrática.

Os discursos da personagem revelam a consciência que absorve os movimentos do espaço social que a forma. Assim, Enjolras não apenas dá vazão a uma visão humanista crítica e utópica da realidade que o circunda - por meio da qual o leitor enxerga essa realidade - como também almeja a mudança desse cenário e impacta a luta do grupo com sua liderança inspiradora, apta a promover a transformação necessária de todos os presentes na barricada para concretizar a revolução.

Portanto, a partir de uma abordagem histórica de cunho político e social sobre a realidade francesa do século XIX, em Les Misérables não apenas está retratado autenticamente o povo, mas também são resgatadas sua memória e identidade por meio da retomada da própria ideia de cidadania: toda essa coletividade composta pelos miseráveis 
que, representados na figura do jovem revolucionário utópico, engendram a mais lídima luta por seus direitos políticos.

\section{REFERÊNCIAS}

BAKHTIN, Mikhail. Estética da criação verbal. São Paulo: Martins Fontes, 2003.

BASTOS, Alcmeno. Introdução ao romance histórico. Rio de Janeiro: EdUERJ, 2007.

BENJAMIN, Walter. Magia e técnica, arte e política: ensaios sobre literatura e história da cultura. São Paulo: Brasiliense, 1985.

CANDIDO, Antonio. "A personagem do Romance". In: (org.). A personagem de ficção. 2. ed. São Paulo: Perspectiva, 2002, p. 51-80.

CARPEAUX, Otto Maria. "Prosa e Fiç̧ão do Romantismo". In: GUINSBURG, J. (org.). O romantismo. 2. ed. São Paulo: Perspectiva, 1978, p. 157-166.

História da Literatura Ocidental. 3. ed. v. III. Brasília: Senado Federal, 2008.

DALLARI, Dalmo de Abreu. Elementos de teoria geral do Estado. São Paulo: Saraiva, 2011.

HOUAISS, A.; VILLAR, M. S. Dicionário Houaiss de Língua Portuguesa. Rio de Janeiro: Objetiva, 2009.

HUGO, Victor. LesMisérables. Paris: Pocket France, 2013 (1862).

LUKÁCS, György. O romance histórico. São Paulo: Boitempo, 2011.

MONTESQUIEU, Charles Louis de Secondat, Baron de la. De l'esprit des lois. Paris: Gallimard, 1995.

PARENT, Yvette. Des mots et des maux dans Les Misérables de Victor Hugo, fragments d'un discours au peuple à travers les noms abstraits de la politique et le vocabulaire social. 2013. 473f. v. 1. Tese (Doutorado em Literatura francesa e francófona) - Escola doutoral de Artes, Letras e Línguas, Universidade da Bretanha Ocidental, Brest, 2013.

POLLAK, Michael. "Memória e identidade social". Disponível em: <http://bibliotecadigital.fgv.br/ojs/index.php/reh/article/view/1941>. Acesso em: 1 maio 2018 (1992). p. 200-212.

REUTER, Yves. Introdução à análise do romance. São Paulo: Martins Fontes, 1996.

ROSENFELD, Anatol. "Literatura e personagem". In: CANDIDO, A. (org.). A personagem de fiç̧ão. 2. ed. São Paulo: Perspectiva, 2002, p. 9-50. 
TROUILLEZ, Édouard; DEHAIS, Annick. Le Robert micro poche: dictionnaire d'apprentissage du français. Paris: Dictionnaires Le Robert, 2013.

ZÉRAFFA, Michel. Pessoa e personagem: o romanesco dos anos 1920 aos anos de 1950. São Paulo: Perspectiva, 2010.

Artigo recebido em: 31 de maio de 2018. Artigo aprovado em: 06 de julho de 2018. 